Article

\title{
Evolution of Microstructure and Mechanical Properties of Mg-6Al Alloy Processed by Differential Speed Rolling upon Post-Annealing Treatment
}

\author{
Honglin Zhang ${ }^{1}$, Zhigang $\mathrm{Xu}{ }^{1, * \mathbb{C}}$, Sergey Yarmolenko ${ }^{1}$, Laszlo J. Kecskes ${ }^{2}$ and Jagannathan Sankar ${ }^{1}$ \\ 1 Department of Mechanical Engineering, North Carolina A\&T State University, Greensboro, NC 27411, USA; \\ hzhang2@aggies.ncat.edu (H.Z.); sergey@ncat.edu (S.Y.); sankar@ncat.edu (J.S.) \\ 2 Hopkins Extreme Materials Institute, The Johns Hopkins University, Baltimore, MD 21218, USA; \\ lkecske1@jhu.edu \\ * Correspondence: zhigang@ncat.edu; Tel.: +86-1336-285-3224
}

Citation: Zhang, H.; Xu, Z.; Yarmolenko, S.; Kecskes, L.J.;

Sankar, J. Evolution of Microstructure and Mechanical Properties of Mg-6Al Alloy Processed by Differential Speed Rolling upon Post-Annealing Treatment. Metals 2021, 11, 926. https://doi.org/10.3390/met11060926

Academic Editor: Zhengyi Jiang

Received: 26 April 2021

Accepted: 2 June 2021

Published: 7 June 2021

Publisher's Note: MDPI stays neutral with regard to jurisdictional claims in published maps and institutional affiliations.

Copyright: (c) 2021 by the authors. Licensee MDPI, Basel, Switzerland. This article is an open access article distributed under the terms and conditions of the Creative Commons Attribution (CC BY) license (https:/ / creativecommons.org/licenses/by/ $4.0 /)$.

\begin{abstract}
Magnesium-6 wt.\% aluminum (Mg-6Al) alloy plates with a 6-millimeter thickness were processed from an initial 12-millimeter thickness by differential speed rolling (DSR), with a 0.76-millimeter thickness reduction per pass using a speed ratio of 2 , preheating temperature of $315^{\circ} \mathrm{C}$, and roll temperature of $265^{\circ} \mathrm{C}$. The effects of annealing temperature of 250,275 , and $300{ }^{\circ} \mathrm{C}$ with a corresponding holding time of $15 \mathrm{~min}$ on the microstructure, texture, and mechanical properties were investigated. Key results show that dynamic recrystallization (DRX) occurred during the roll processing, resulting in a greatly reduced grain size. In addition, the basal pole of the as-rolled plate was inclined to the rolling direction (RD) by $\sim 20^{\circ}$, due to the shear strain introduced during DSR. Subsequent annealing caused grain growth, eliminated the basal pole inclination towards the RD, and slightly increased the pole intensity. Compared with the as-rolled plate, the average of the ultimate tensile strength (UTS) and the yield strength (YS) of the annealed plates decreased, while the average elongation at fracture $\left(\varepsilon_{\mathrm{f}}\right)$ increased. With the annealing temperature of $275^{\circ} \mathrm{C}$, the plate achieved a good combination of mechanical properties with UTS, YS, and $\varepsilon_{\mathrm{f}}$ being $292.1 \mathrm{MPa}, 185.0 \mathrm{MPa}$, and $24.9 \%$, respectively. These results suggest that post-roll annealing is an effective way to improve the mechanical response of this $\mathrm{Mg}$ alloy processed by DSR.
\end{abstract}

Keywords: magnesium alloys; differential speed rolling; annealing; mechanical properties

\section{Introduction}

Magnesium (Mg) alloys have a great potential for use as structural materials, particularly in automotive and aerospace industrial applications, owing to their low density and high specific strength [1,2]. However, due to the hexagonal close-packed (HCP) crystal structure, wrought $\mathrm{Mg}$ alloys exhibit poor formability at room temperature. Currently, their formability can be greatly enhanced through grain refinement and texture control with proper thermoplastic deformation processing, such as extrusion [3], equal channel angular extrusion (ECAE) [4], equal speed rolling (ESR), and differential speed rolling (DSR) [5-7]. DSR is carried out at different rotational speeds for the upper and lower rolls, so that a shear strain can be introduced during the thickness reduction process, leading to different inclinations of the basal pole of the processed plate material from those processed by conventional rolling [8], thus enhancing their formability $[9,10]$.

Generally, the DSR method is used in materials' processing to impart high-strength through grain refinement and to control the as-deformed texture [11]. Kim et al. [12] revealed that in copper, a sub-micrometer grain size of $820 \mathrm{~nm}$ could be achieved after a $65 \%$ thickness reduction using single-pass rolling via DSR with a speed ratio of 3 . Gong et al. [13] reported that for ZK60 alloys, the elongation of a DSR-processed plate with a speed ratio of 1.5 was $69.2 \%$ higher than that of an ESR-processed plate. Huang et al. [14] 
obtained a superior combination of high strength (tensile strength: $329 \mathrm{MPa}$ ) and high ductility (fracture elongation: 25\%) in DSR-processed AZ80 alloy plates, which was much improved compared to the case of ESR-processed equivalents under the same thickness reduction per pass. In recent years, extensive works on various $\mathrm{Mg}$ alloys, especially those containing $\mathrm{Al}$ and $\mathrm{Zn}$ additions-e.g., AZ31 [9,15-17], AZ91 [18], AM31 [19,20], and ZK60 [21-23] alloys-demonstrated that DSR processing has a great impact on the texture and mechanical properties of these materials. It was established that a basal texture weakening effect with higher speed ratios was attributed to extensive tension twinning that occurred during DSR processing, which was not found in ESR materials. Consequently, DSR-processed Mg alloy plates are characterized not only by more refined microstructures but also by exceptionally high strengths combined with enhanced plasticity [24]. Therefore, DSR processing is considered to be one of the most effective techniques for the processing of $\mathrm{Mg}$ materials.

However, through such plastic deformation processing, the as-processed Mg alloy plates will still have general issues, such as a non-homogeneous microstructure, internal stresses, or strain hardening, which will considerably influence the subsequent processing steps. Post-annealing treatment is a commonly used way to release the residual stresses and reduce the work-hardening capacity by static recrystallization. Studies on AZ31 by Qing et al. [25] and Kim et al. [26] showed that the fracture elongation of the annealed plates was $52.1 \%$ higher than that of the as-rolled plate. Chen and Yang et al. $[27,28]$ reported that enhanced ductility can be obtained through control of the annealing temperature and holding time. Yoshihara et al. [29] showed that careful selection of the appropriate annealing conditions was beneficial in eliminating the internal stresses and decreasing work-hardening, finally resulting in the improved formability of $\mathrm{Mg}$ alloys.

The aim of this paper was to investigate the effect of different annealing temperatures on the microstructure, texture evolution, and mechanical properties of the DSR-processed $\mathrm{Mg}-6 \mathrm{Al}$ alloy plates. The results will help to elucidate key aspects of the deformation process and to understand how much improvement in mechanical properties for the materials processed by DSR could be obtained after optimized heat treatment.

\section{Materials and Methods}

The Mg-6 Al (wt. \%) alloy used in this study was fabricated by melting high-purity Mg (99.97\%, US Magnesium, Salt Lake, UT, USA) and Al (99.999\%, Alfa Aesar, Ward Hill, MA, USA) at $730{ }^{\circ} \mathrm{C}$ and casting the melt into a preheated permanent steel mold in an argon-filled glove box, as we performed previously for other Mg-based alloys [30]. Specifically, pure $\mathrm{Mg}$ was melted at $730^{\circ} \mathrm{C}$ followed by the addition of pure $\mathrm{Al}$, held for $10 \mathrm{~min}$, and then mechanically stirred for $15 \mathrm{~min}$ to homogenize the melt. This, in turn, was followed by extra dwelling at $690^{\circ} \mathrm{C}$ for $1 \mathrm{~h}$. Before casting, the temperature of the melt was raised to $730{ }^{\circ} \mathrm{C}$. The melt was cast through a magnesia foam filter (15 pores per inch) into a steel book mold preheated to $250{ }^{\circ} \mathrm{C}$. Plates with dimensions of $60 \mathrm{~mm}$ (length) $\times 50 \mathrm{~mm}$ (width) $\times 12 \mathrm{~mm}$ (thickness) were cut from the as-cast ingots as starting materials. In order to improve the uniformity of the microstructure, the as-cast plates were homogenized at $385^{\circ} \mathrm{C} \times 6 \mathrm{~h}+430^{\circ} \mathrm{C} \times 15 \mathrm{~h}$ and then quenched in water.

The diameters of the upper and lower rolls were identical $(100 \mathrm{~mm})$ and the speed ratio between the upper and the lower rolls was set as 2 . The rolls were maintained at a constant temperature of $265^{\circ} \mathrm{C}$ by resistance-heating elements that were embedded inside the rolls. No lubrication was applied during rolling. The plates were first preheated to $315^{\circ} \mathrm{C}$ for $5 \mathrm{~min}$ and then fed between the rolls with a thickness reduction of $0.76 \mathrm{~mm}$ per pass. The plates were then reheated for $5 \mathrm{~min}$ and rotated $180^{\circ}$ around the rolling direction (RD) for each subsequent pass, which is considered to be the most effective route to obtain an equiaxed, homogeneous, and fine-grained microstructure [31] due to the cross-shear strain being exerted. It is worth noting that instead of using a constant thickness reduction ratio (i.e., constant compressive strain) per pass, a constant thickness reduction per pass was used in this effort. After about 8 passes, a 50\% total thickness reduction of the plates 
was achieved. These plates were then used for the heat treatment experiments performed at 250,275 , and $300{ }^{\circ} \mathrm{C}$ for a fixed $15 \mathrm{~min}$.

Microstructural analyses were performed on the normal plane (ND plane), as illustrated in Figure 1. The metallographic samples were prepared by a standard mechanical grinding procedure with $\mathrm{SiC}$ papers from 30 to $1 \mu \mathrm{m}$ grit size and finally polished with a 0.05 -micrometer grit $\mathrm{Al}_{2} \mathrm{O}_{3}$ suspension. The polished samples were then etched using $10 \%$ nitric acid in isopropanol. Microstructural features were characterized using optical microscopy (OM, AxioCam MRC5, Zeiss, Jena, German), scanning electron microscopy (SEM, Hitachi, SU8000, Tokyo, Japan), and energy-dispersive X-ray spectroscopy (EDS). Next, electron backscatter diffraction (EBSD, Symmetry, High Wycombe, UK) was carried out on the ND plane for measurements of the grain size and texture. The samples for EBSD were first polished in the same manner as those for OM, followed by further polishing with an ion mill (Fischione, Model1061 SEM Mill, Export, USA) for 25 min with the parameters of $3 \mathrm{kV}$ and $3^{\circ}$ tilt. Lastly, the tensile mechanical properties of the plates were evaluated using an Instron 5569 universal testing machine with a strain rate of $1 \times 10^{-2} \mathrm{~s}^{-1}$. The tensile samples were cut from the rolled plates at $0^{\circ}(\mathrm{RD}), 45^{\circ}$, and $90^{\circ}$ (transverse direction, TD) (as seen in Figure 1). Testing was repeated with three specimens prepared for each condition.

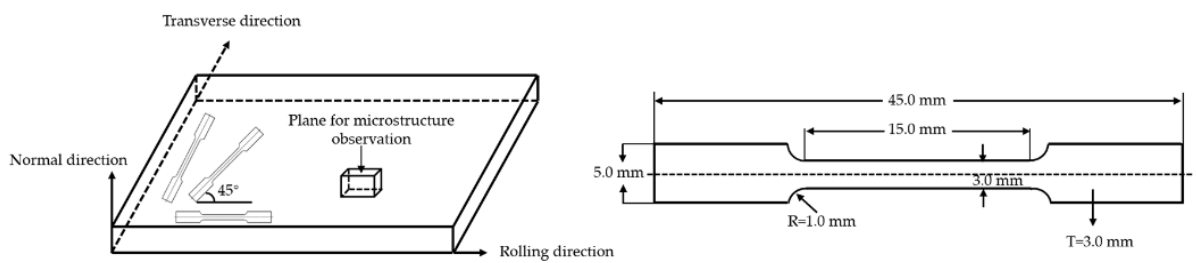

Figure 1. Schematic showing the sample extraction plan for mechanical testing and microstructure analysis (left), and the dimensions of the tensile testing samples (right).

\section{Results}

\subsection{Microstructure}

\subsubsection{Microstructure of the Starting Material}

Figure 2 shows the starting $\mathrm{Mg}-6 \mathrm{Al}$ alloy plate after homogenization. As shown in the optical micrograph in Figure 2a, the alloy was fully homogenized and the grain boundaries were clearly visible. The grain size determined by the linear interception method was in the range of 300 400 $\mu \mathrm{m}$. Figure $2 \mathrm{~b}$ shows the corresponding SEM micrograph. It is clearly seen that the second phase was almost dissolved into the $\mathrm{Mg}$ matrix, leaving only limited sporadic bright particles distributed along the grain boundaries. Figure 3 shows an EDS mapping of the alloy, and the calculated chemical composition is listed in Table 1, which shows that the weight percentage of the $\mathrm{Al}$ element in the selected area is $6.14 \mathrm{wt} . \%$, which is close to the nominal composition (6 wt.\%).

(a)
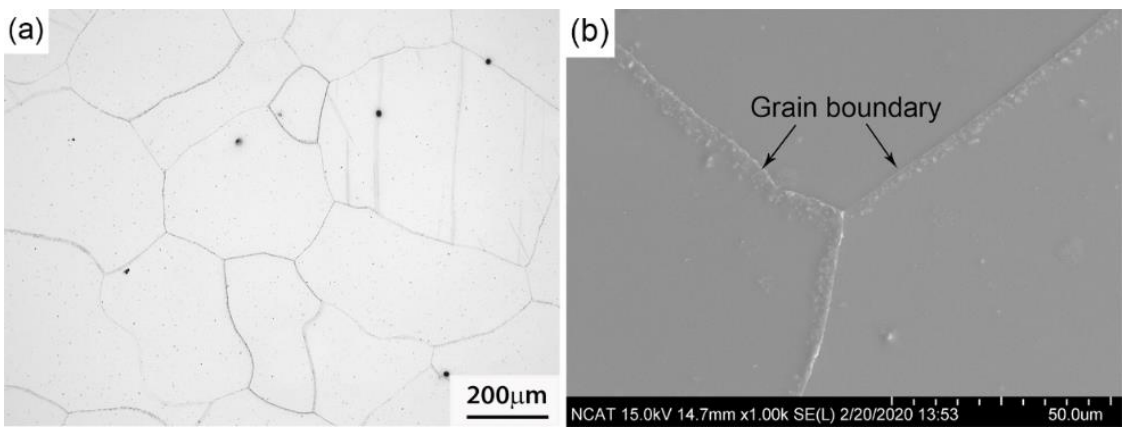

Figure 2. Microstructures of the starting homogenized plate by OM in (a) and SEM in (b). 

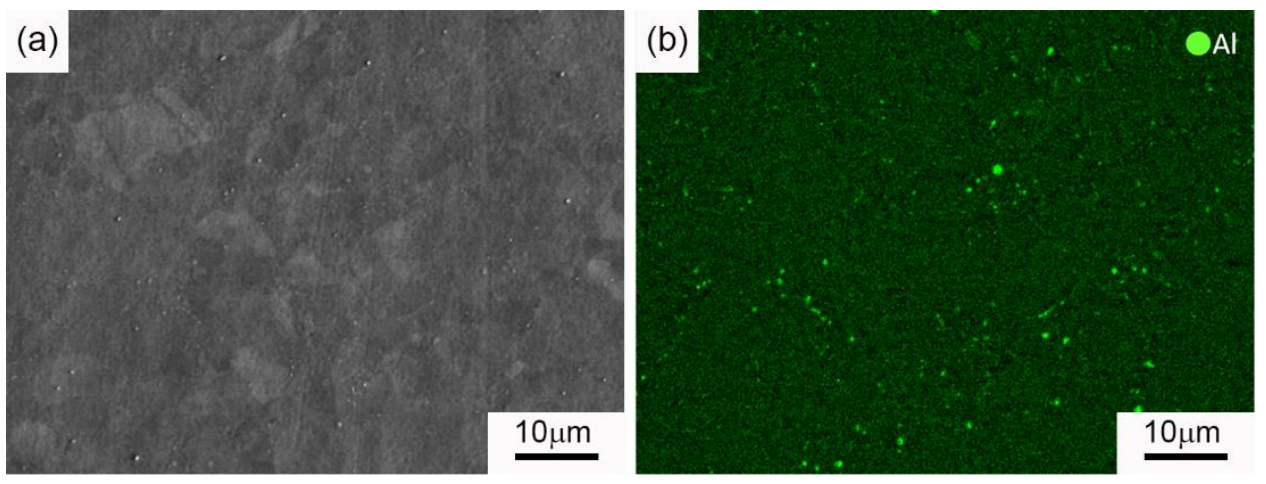

Figure 3. (a) SEM micrograph and (b) EDS mapping of a rolled Mg-6Al plate.

Table 1. The EDS results of the elemental analysis.

\begin{tabular}{cc}
\hline Element & Fraction (wt.\%) \\
\hline $\mathrm{Mg}$ & $93.86 \pm 0.08$ \\
$\mathrm{Al}$ & $6.14 \pm 0.08$ \\
\hline
\end{tabular}

\subsubsection{Microstructure of the Rolled and Annealed Materials}

Figure 4 presents SEM images of the as-rolled plate and that which annealed at $300{ }^{\circ} \mathrm{C}$. As can be seen, numerous spherical second-phase particles with a size smaller than $0.5 \mu \mathrm{m}$ were observed at the grain boundaries and inside grains. It is worth noting that after annealing at $300{ }^{\circ} \mathrm{C}$ (Figure $4 \mathrm{~b}$ ), the second-phase particles still exist. The reason for this may be that it takes at least approximately $40 \mathrm{~h}$ to achieve the complete dissolution of the second phase due to the low diffusion rate of $\mathrm{Al}$ atoms in the $\mathrm{Mg}$ matrix for $\mathrm{Mg}-\mathrm{Al}$ alloys [32]. In this study, annealing at $300^{\circ} \mathrm{C}$ for $15 \mathrm{~min}$ was not sufficient for full dissolution of the $\mathrm{Al}$ atoms in the $\mathrm{Mg}$ matrix. EDS analysis was used to identify the second-phase precipitates, as seen in Figure 5a. According to the Mg and Al elemental maps (Figure 5b,c, respectively), the second-phase precipitates $(<1 \mu \mathrm{m})$ consisted of high concentrations of $\mathrm{Al}$. The corresponding EDS point analysis results (Figure $5 \mathrm{~d}$ ) reveal that the composition of the second phase is very close to the weight fraction of $\mathrm{Mg}_{17} \mathrm{Al}_{12}$, so the second phase could be considered the $\mathrm{Mg}_{17} \mathrm{Al}_{12}$ intermetallic phase according to the $\mathrm{Mg}$ - $\mathrm{Al}$ phase diagram [33].
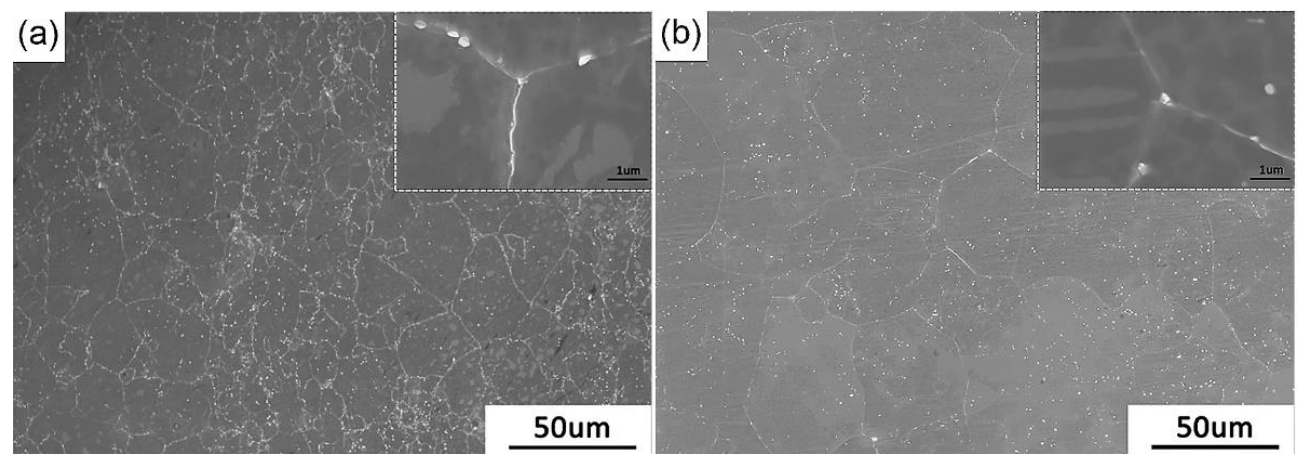

Figure 4. SEM images of the Mg-6Al plate (a) as-rolled and (b) annealed at $300{ }^{\circ} \mathrm{C}$. Corresponding high-magnification images are shown in the insets. 

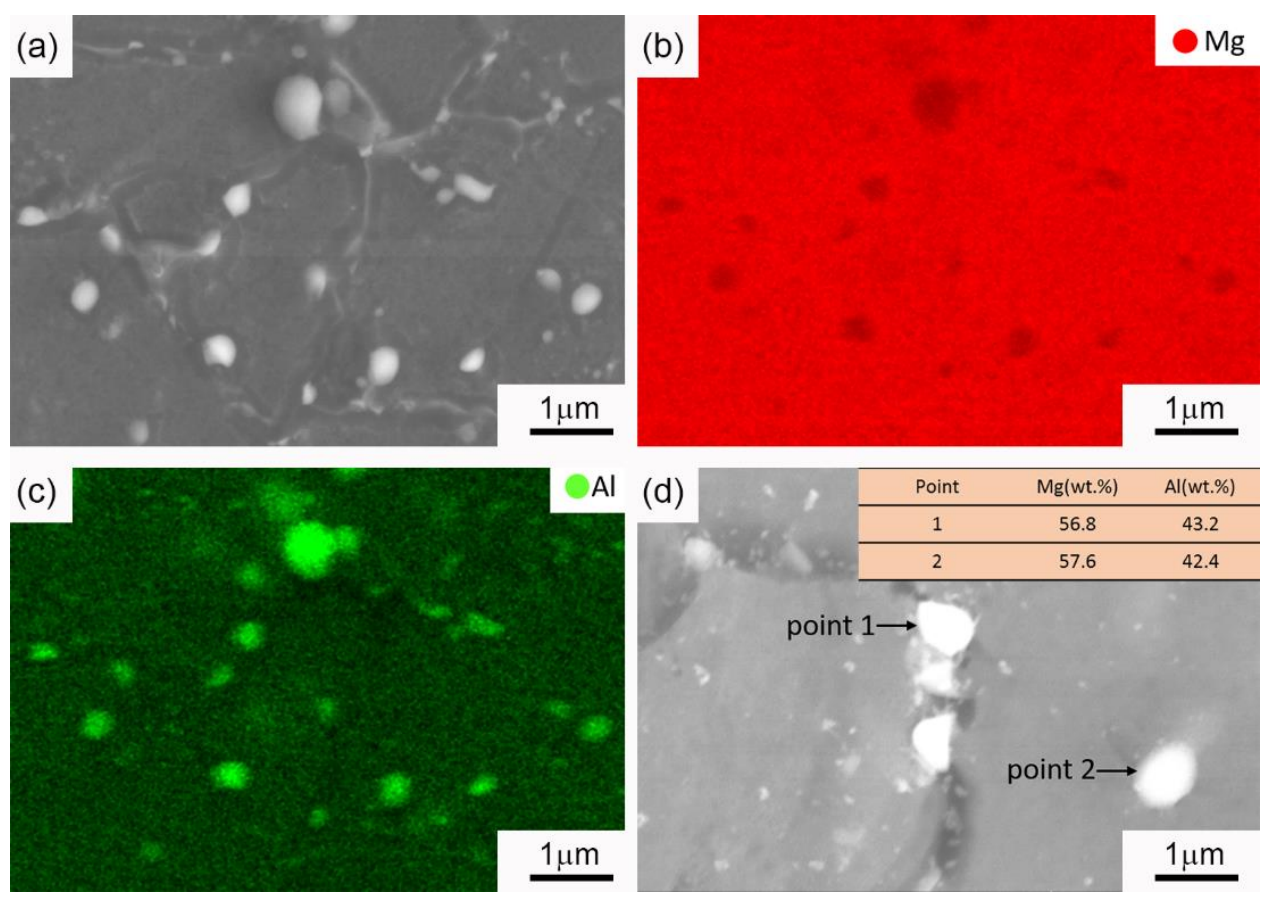

Figure 5. EDS analysis results of the as-rolled Mg-6Al plates: (a) SEM image, with corresponding elemental maps: (b) $\mathrm{Mg}$, (c) $\mathrm{Al}$, and (d) point analysis results of the second-phase precipitates.

Figure 6 shows the EBSD inverse pole figure (IPF) maps on the ND plane of the as-rolled and annealed plates. The different colors represent different orientations of the grains. The near-identically colored grains indicate that the mismatch in orientation between these grains is insignificant. Firstly, the microstructure of the as-rolled plate (Figure 6a) was greatly refined compared to that in the homogenized state (Figure 2a), indicating the occurrence of dynamic recrystallization (DRX). Beer et al. [34] and Samman et al. [35] reported that dislocations accumulate near grain boundaries and rearrange through cross-slip and climb during hot deformation processing, which then form into low-angle grain boundaries. In turn, these low-angle grain boundaries can be further transformed into high-angle grain boundaries by continuously absorbing new dislocations, which then form into new DRXed grains. Secondly, as seen in Figure 6b, annealing of the as-rolled plate resulted in equiaxial grains, indicating that homogeneous nucleation and grain growth occurred during static recrystallization (SRX). Especially for the plates annealed at 275 (Figure $6 \mathrm{c}$ ) and $300{ }^{\circ} \mathrm{C}$ (Figure 6d), there was remarkable grain growth. The grain size distributions of the as-rolled and annealed plates obtained from post-EBSD analysis are also shown as histograms adjacent to the micrographs. The average grain size of the as-rolled plate was $9.1 \mu \mathrm{m}$, while for the plates annealed at 250,275 , and $300{ }^{\circ} \mathrm{C}$, average grain sizes of $12.1,24.8$, and $36.6 \mu \mathrm{m}$ were observed, respectively. 

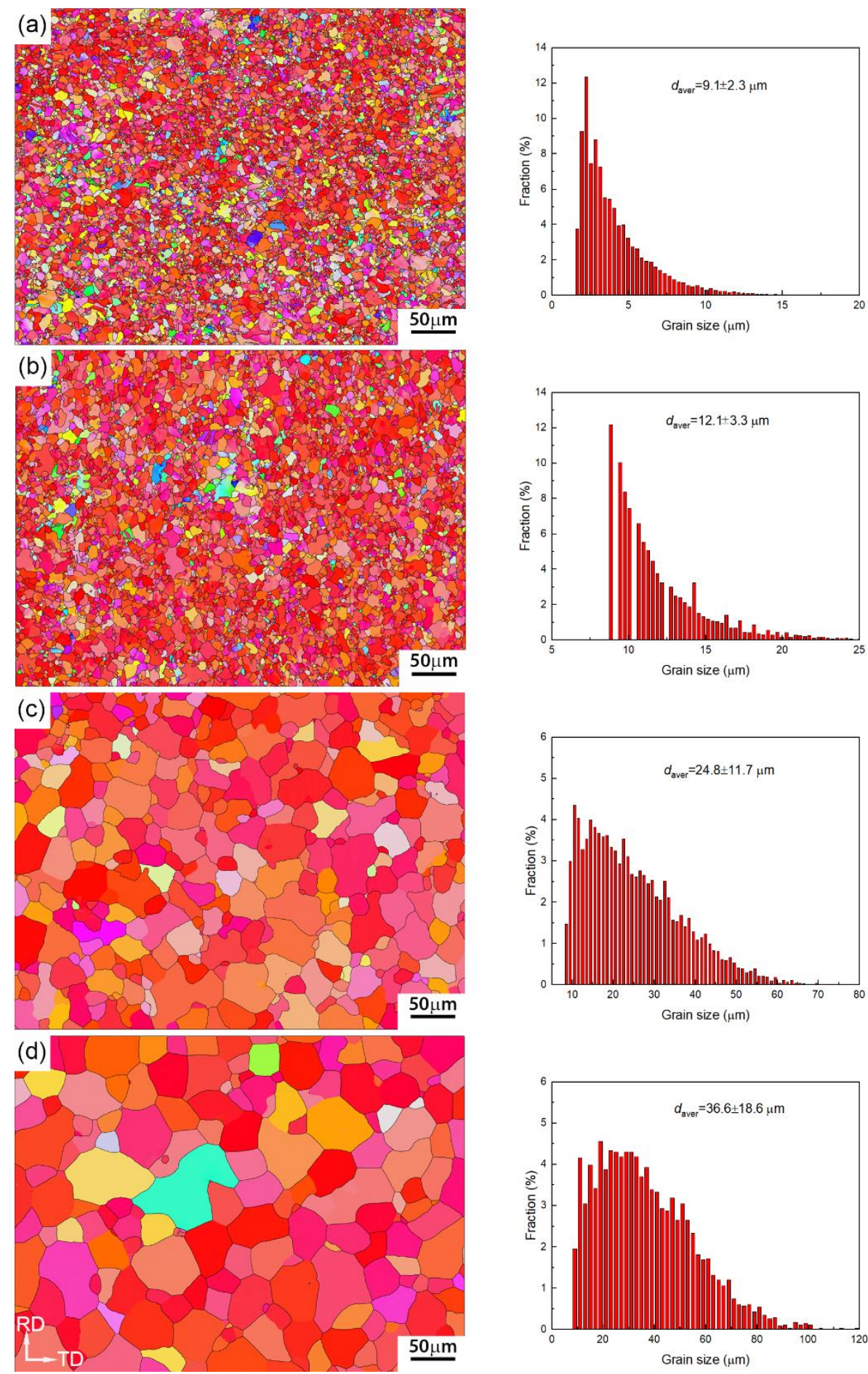

Figure 6. Inverse pole figure (IPF) maps on the ND plane of the Mg-6Al alloy plates (on the left) and corresponding grain size distributions (on the right) for the conditions: (a) as-rolled, with the same plate annealed: (b) $250{ }^{\circ} \mathrm{C}$, (c) $275^{\circ} \mathrm{C}$, and (d) $300{ }^{\circ} \mathrm{C}$ for a fixed time of $15 \mathrm{~min}$.

\subsection{Texture Evolution}

Figure 7 shows the pole figures of the as-rolled and annealed plates. It can be seen that all the plates displayed a strong basal texture, indicating that the c-axis was approximately along the normal direction. Moreover, it can be noticed that the basal texture of the as-rolled plate was tilted towards the RD by $\sim 20^{\circ}$. However, there was a change in the basal texture inclination for the annealed plates. It decreased to $\sim 10^{\circ}$. The maximum pole intensity of 
the as-rolled plate was about 9.42. After annealing at 250,275 , and $300{ }^{\circ} \mathrm{C}$, there was a slight increase in pole intensities, which were about 11.90, 11.03, and 11.73, respectively.
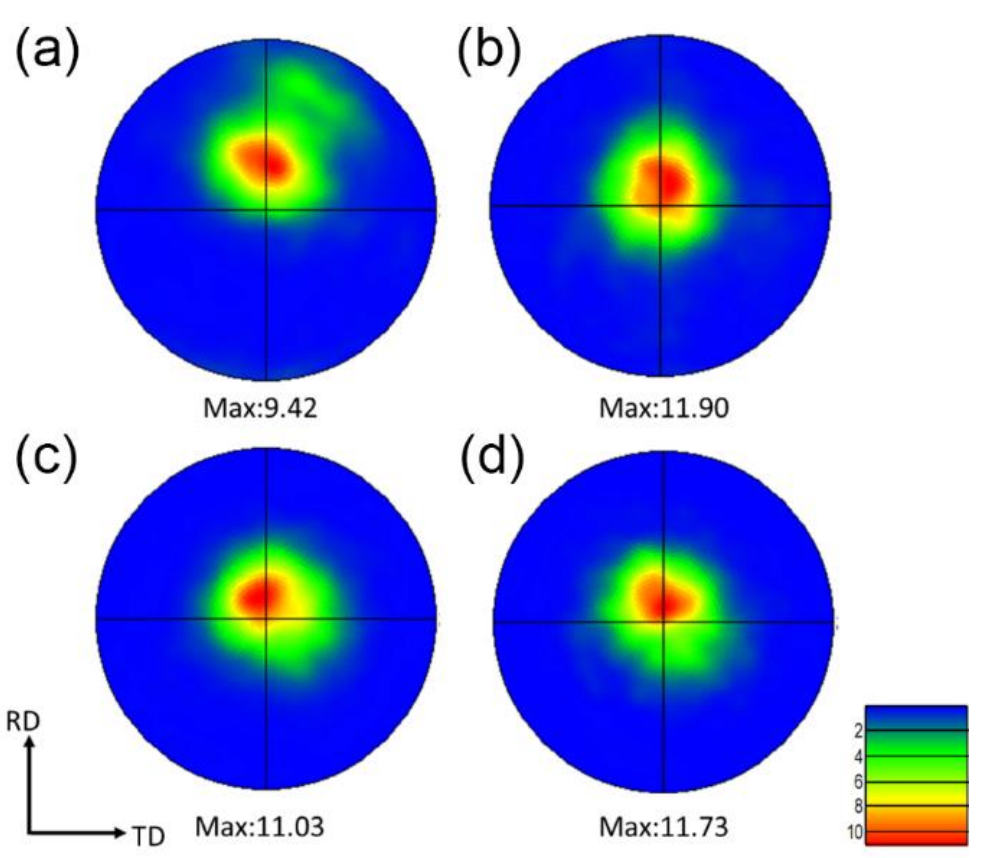

Figure 7. $\{0001\}$ pole figures of the plates: (a) as-rolled, with the same plate annealed: (b) $250{ }^{\circ} \mathrm{C}$, (c) $275^{\circ} \mathrm{C}$, and (d) $300{ }^{\circ} \mathrm{C}$ for a fixed time of $15 \mathrm{~min}$.

\subsection{Mechanical Properties}

Figure $8 \mathrm{a}-\mathrm{c}$ show the engineering in-plain stress-strain curves of the as-rolled and annealed plates in tensile directions of $0^{\circ}, 45^{\circ}$, and $90^{\circ}$ relative to the $R D$; the ultimate tensile strength (UTS) and fracture elongation $(\varepsilon)$ are also shown in Figure $8 \mathrm{~d}$. The detailed mechanical properties are listed in Table 2. The weighted average values of UTS $\mathrm{Sver}_{\text {aver, }}$, and $\varepsilon_{\text {aver }}$ were calculated using $\left(\mathrm{UTS}_{0^{\circ}}+2 \mathrm{UTS}_{45^{\circ}}+\mathrm{UTS}_{90^{\circ}}\right) / 4,\left(\mathrm{YS}_{0^{\circ}}+2 \mathrm{YS}_{45^{\circ}}+\mathrm{YS}_{90^{\circ}}\right) / 4$, and $\left(\varepsilon_{\mathrm{f} 0^{\circ}}+2 \varepsilon_{\mathrm{f} 45^{\circ}}+\varepsilon_{90^{\circ}}\right) / 4$, respectively. Without exception, all the specimens deformed by basal slip. Furthermore, the tensile strength and elongation were nearly the same regardless of the different tensile directions for the as-rolled and annealed plates, indicating very little in-plane anisotropy and a weak effect of the texture. Specifically, for the as-rolled plate, the $\mathrm{UTS}_{\text {aver, }} \mathrm{YS}_{\text {aver, }}$ and $\varepsilon_{\text {aver }}$ were about $307.0 \mathrm{MPa}, 213.1 \mathrm{MPa}$, and $15.3 \%$, respectively. After annealing at $250{ }^{\circ} \mathrm{C}$, the $\mathrm{UTS}_{\text {aver }}$ and $\mathrm{YS}_{\text {aver }}$ slightly decreased to 303.9 and $198.1 \mathrm{MPa}$, while the $\varepsilon_{\text {aver }}$ improved to $15.8 \%$. With a further increase in the annealing temperature to $275{ }^{\circ} \mathrm{C}$, the $\mathrm{UTS}_{\text {aver }}$ and $\mathrm{YS}_{\text {aver }}$ noticeably decreased to 292.1 and $185.0 \mathrm{MPa}$, while the $\varepsilon_{\text {aver }}$ had a remarkable increase to $24.9 \%$. When annealed at $300{ }^{\circ} \mathrm{C}$, the $\mathrm{UTS}_{\text {aver, }} \mathrm{YS}_{\text {aver, }}$, and $\varepsilon_{\text {aver }}$ all decreased to $285.5 \mathrm{MPa}, 162.9 \mathrm{MPa}$, and $20.9 \%$, respectively, compared to the values at $275^{\circ} \mathrm{C}$. Thus, it can be inferred that the best possible combination of strength and elongation was achieved for the case of annealing at $275^{\circ} \mathrm{C}$. 
(a)

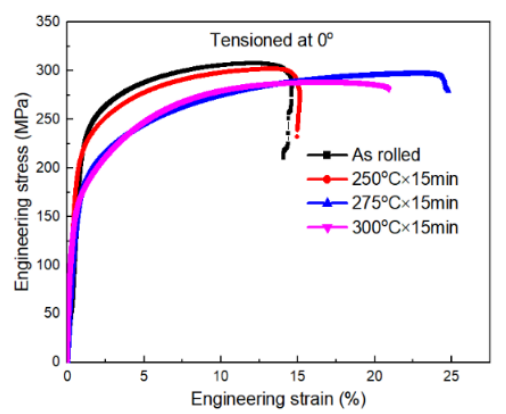

(c)

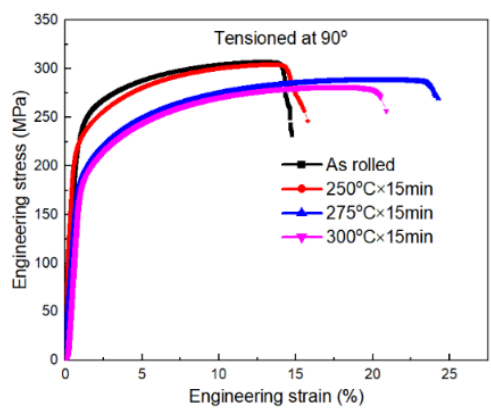

(b)

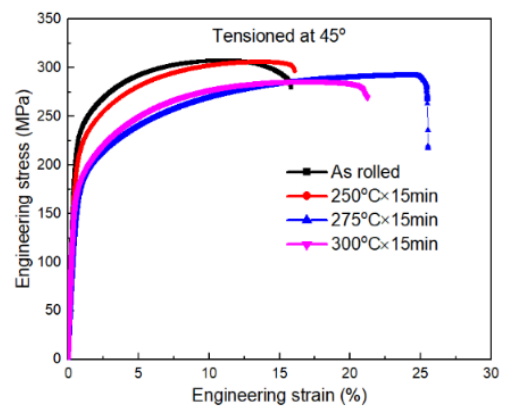

(d)

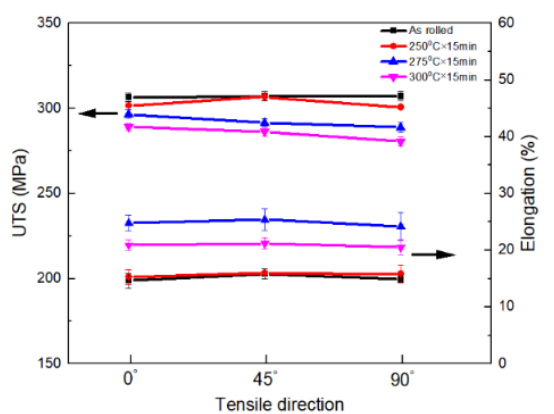

Figure 8. In-plane engineering stress-strain curves of the as-rolled plate and annealed plates in the tensile directions of (a) $0^{\circ}$, (b) $45^{\circ}$, and (c) $90^{\circ}$ relative to the $\mathrm{RD}$, and (d) the trends of the ultimate strength and elongation to failure in the three directions.

Table 2. Results of Tensile Testing of the Mg-6Al DSR Samples Carried out along $0^{\circ}, 45^{\circ}$ and $90^{\circ}$.

\begin{tabular}{|c|c|c|c|c|c|c|c|c|c|c|c|c|}
\hline \multirow{2}{*}{ Plate * } & \multicolumn{3}{|c|}{ UTS (MPa) } & \multirow{2}{*}{$\begin{array}{l}\text { UTS }_{\text {aver }} \\
\text { (MPa) }\end{array}$} & \multicolumn{3}{|c|}{ YS (MPa) } & \multirow{2}{*}{$\begin{array}{l}\mathrm{YS}_{\mathrm{aver}} \\
(\mathrm{MPa})\end{array}$} & \multicolumn{3}{|c|}{$\varepsilon(\%)$} & \multirow{2}{*}{$\varepsilon_{\text {aver }}(\%)$} \\
\hline & $0^{\circ}$ & $45^{\circ}$ & $90^{\circ}$ & & $0^{\circ}$ & $45^{\circ}$ & $90^{\circ}$ & & $0^{\circ}$ & $45^{\circ}$ & $90^{\circ}$ & \\
\hline $\begin{array}{c}\text { As- } \\
\text { rolled }\end{array}$ & $\begin{array}{c}306.4 \pm \\
2.6\end{array}$ & $\begin{array}{c}307.3 \pm \\
2.7\end{array}$ & $\begin{array}{c}307.0 \pm \\
2.6\end{array}$ & $\begin{array}{c}307.0 \pm \\
2.7\end{array}$ & $\begin{array}{c}213.6 \pm \\
2.3\end{array}$ & $\begin{array}{c}211.5 \pm \\
2.5\end{array}$ & $\begin{array}{c}215.7 \pm \\
2.9\end{array}$ & $\begin{array}{c}213.1 \pm \\
2.6\end{array}$ & $\begin{array}{c}14.6 \pm \\
1.3\end{array}$ & $\begin{array}{c}15.8 \pm \\
1.2\end{array}$ & $\begin{array}{c}14.9 \pm \\
1.4\end{array}$ & $\begin{array}{c}15.3 \pm \\
1.3\end{array}$ \\
\hline $\begin{array}{c}250{ }^{\circ} \mathrm{C} \times \\
15 \mathrm{~min}\end{array}$ & $\begin{array}{c}301.6 \pm \\
1.5\end{array}$ & $\begin{array}{c}306.7 \pm \\
2.5\end{array}$ & $\begin{array}{c}300.5 \pm \\
1.7\end{array}$ & $\begin{array}{c}303.8 \pm \\
2.1\end{array}$ & $\begin{array}{c}203.1 \pm \\
2.7\end{array}$ & $\begin{array}{c}196.9 \pm \\
2.6\end{array}$ & $\begin{array}{c}195.4 \pm \\
3.2\end{array}$ & $\begin{array}{c}198.1 \pm \\
2.8\end{array}$ & $\begin{array}{c}15.3 \pm \\
1.3\end{array}$ & $\begin{array}{c}16.0 \pm \\
1.2\end{array}$ & $\begin{array}{c}15.9 \pm \\
1.5\end{array}$ & $\begin{array}{c}15.8 \pm \\
1.3\end{array}$ \\
\hline $\begin{array}{c}275^{\circ} \mathrm{C} \times \\
15 \mathrm{~min}\end{array}$ & $\begin{array}{c}296.5 \pm \\
2.5\end{array}$ & $\begin{array}{c}291.5 \pm \\
2.1\end{array}$ & $\begin{array}{c}288.8 \pm \\
2.9\end{array}$ & $\begin{array}{c}292.1 \pm \\
2.4\end{array}$ & $\begin{array}{c}184.2 \pm \\
2.9\end{array}$ & $\begin{array}{c}186.3 \pm \\
2.7\end{array}$ & $\begin{array}{c}183.3 \pm \\
2.8\end{array}$ & $\begin{array}{c}185.0 \pm \\
2.8\end{array}$ & $\begin{array}{c}24.8 \pm \\
1.4\end{array}$ & $\begin{array}{c}25.4 \pm \\
1.8\end{array}$ & $\begin{array}{c}24.2 \pm \\
1.6\end{array}$ & $\begin{array}{c}24.9 \pm \\
1.7\end{array}$ \\
\hline $\begin{array}{c}300{ }^{\circ} \mathrm{C} \times \\
15 \mathrm{~min}\end{array}$ & $\begin{array}{c}289.1 \pm \\
1.9\end{array}$ & $\begin{array}{c}286.2 \pm \\
2.5\end{array}$ & $\begin{array}{c}280.5 \pm \\
2.4\end{array}$ & $\begin{array}{c}285.5 \pm \\
2.3\end{array}$ & $\begin{array}{c}168.9 \pm \\
2.4\end{array}$ & $\begin{array}{c}161.5 \pm \\
3.2\end{array}$ & $\begin{array}{c}159.8 \pm \\
2.9\end{array}$ & $\begin{array}{c}162.9 \pm \\
2.9\end{array}$ & $\begin{array}{c}20.9 \pm \\
1.2\end{array}$ & $\begin{array}{c}21.2 \pm \\
1.4\end{array}$ & $\begin{array}{c}20.5 \pm \\
1.4\end{array}$ & $\begin{array}{c}20.9 \pm \\
1.4\end{array}$ \\
\hline
\end{tabular}

* The composition of the Mg-6Al samples was fixed.

\section{Discussion}

\subsection{Microstructure and Texture}

First to point out that the cross-section of the as-rolled plate would contain a strain gradient through the thickness, especially in the RD, due to the nature of the DSR process. The presence of this strain gradient is confirmed by the forward tilt of the basal pole (Figure 7a). However, due to the realignment of the basal poles (Figure $7 \mathrm{~b}-\mathrm{d}$ ) upon annealing, the residual effects of the through-thickness gradient are likely removed from the bulk of the plates. The residual strain is a significant driver for rapid grain growth. Any remaining effect, given the large number of grains in the gauge sections, would have appeared as differences in the stress_-strain curves of the samples with the gradient $\left(0^{\circ}\right.$ - parallel to RD) and without the gradient (90 - parallel to TD). However, the similarities between the $0^{\circ}$ (parallel to RD) and $90^{\circ}$ (parallel to TD) tensile specimen data show little to no variability in the overall YS, UTS, and elongation to fracture values. Therefore, the DRX texture is mostly uniform in the bulk; any residual strain would be quickly removed with annealing. In order to confirm this hypothesis, microstructures at five (5) different but evenly spaced positions through the thickness (as shown in Figure S1 in the supplemental materials section) of the as-rolled and annealed plates were examined with EBSD. As 
shown in Figures S2-S5, the average grain size across the thickness does not show obvious differences in each of the plates. This relatively uniform microstructure may be due to the special route used in the roll processing. In particular, the plate was rotated by $180^{\circ}$ along the rolling direction for each subsequent pass. Moreover, the number of the total rolling passes is even (8 passes). Further, by inspecting the $\{0001\}$ pole figures of the as-rolled and annealed plates in Figures S6-S9, it is found that all pole intensities across the thickness are close to each other for the annealed samples. An outlier is the pole intensity of the as-rolled plate at the upper position which is slightly lower than those in the other positions. It is also interesting to note that the pole centers across the thickness do not show much difference for each of the plates in both the as-rolled or the annealed conditions. The above observations prove that the materials used in this work are relatively uniform in both the average grain size and the texture through the plate thickness.

In addition, the pole intensities of the annealed plates were slightly higher than that of the as-rolled plate, as seen in Figure 7. This may be related to grain growth during the annealing process (as seen in Figure 6). It has been reported [36-40] that the coarsening of DRXed grains strengthens the basal texture during subsequent heat treatment. Additionally, the basal pole of all the plates was inclined toward the RD due to the intense shear strain during DSR processing, but the inclination angle was reduced after annealing. Previous research also showed that for the basal textures that form, the c-axis inclines by various degrees away from the ND towards the RD in DSR-processed Mg alloy sheets, such as AZ31 [17], ZK60 [41], WE43 [42], or AZ91 [43], which was considered to be a result of the applied shear stress component in DSR. Huang et al. [37] also reported that the inclination of the basal pole gradually decreased and finally moved to the center with the progress of grain growth during subsequent annealing.

\subsection{Mechanical Properties}

It is well known that the yield stress (YS) and fracture elongation $\left(\varepsilon_{\mathrm{f}}\right)$ are mainly dominated by grain size and texture. The effect of grain size on the YS is generally analyzed by the Hall-Petch (H-P) equation [44], which can be calculated as follows:

$$
\sigma_{\mathrm{y}}=\sigma_{0}+\mathrm{k}_{\mathrm{y}} d^{-1 / 2}
$$

where $\sigma_{\mathrm{y}}$ is the yield stress, $\sigma_{0}$ is a material constant for the starting stress for dislocation movement, $\mathrm{k}_{\mathrm{y}}$ is a strengthening coefficient (a constant specific to each material), and $d$ $(\mu \mathrm{m})$ is the average grain size. The value of $\mathrm{k}_{\mathrm{y}}$ in $\mathrm{Mg}$ alloys is rather variable. It is estimated to be 225 and $316 \mathrm{MPa} \mu \mathrm{m}^{1 / 2}$ for the case of rapidly solidified WE43 [45] and ZK60 [27] alloys, respectively.

Figure 9 shows the Hall-Petch relationship for the as-rolled and annealed plates, with $\mathrm{k}_{\mathrm{y}}=267 \mathrm{MPa} \mathrm{m}^{1 / 2}$ and $\sigma_{0}=124.1 \mathrm{MPa}$, which is very close to the reported $127.0 \mathrm{MPa}$ of annealed ZK60 alloy sheets processed by warm rolling [22]. It can be seen that the relationship between $\sigma_{\mathrm{y}}$ and $\mathrm{d}$ was in good agreement with the Hall-Petch relationship. Comparing the grain sizes of the as-rolled and annealed plates at $250^{\circ} \mathrm{C}$ in Figure 3, the average grain sizes were about 9.1 and $12.1 \mu \mathrm{m}$, respectively, so the $\mathrm{YS}$ of the plate annealed at $250^{\circ} \mathrm{C}$ decreased slightly to 199.1 from $213.1 \mathrm{MPa}$ in the as-rolled one. Increasing the annealing temperature to 275 and $300^{\circ} \mathrm{C}$ led to a significant increase in grain sizes, which were about 24.8 and $36.6 \mu \mathrm{m}$, leading to a large decrease in their YS values, which were 195.0 and $162.9 \mathrm{MPa}$, respectively. 


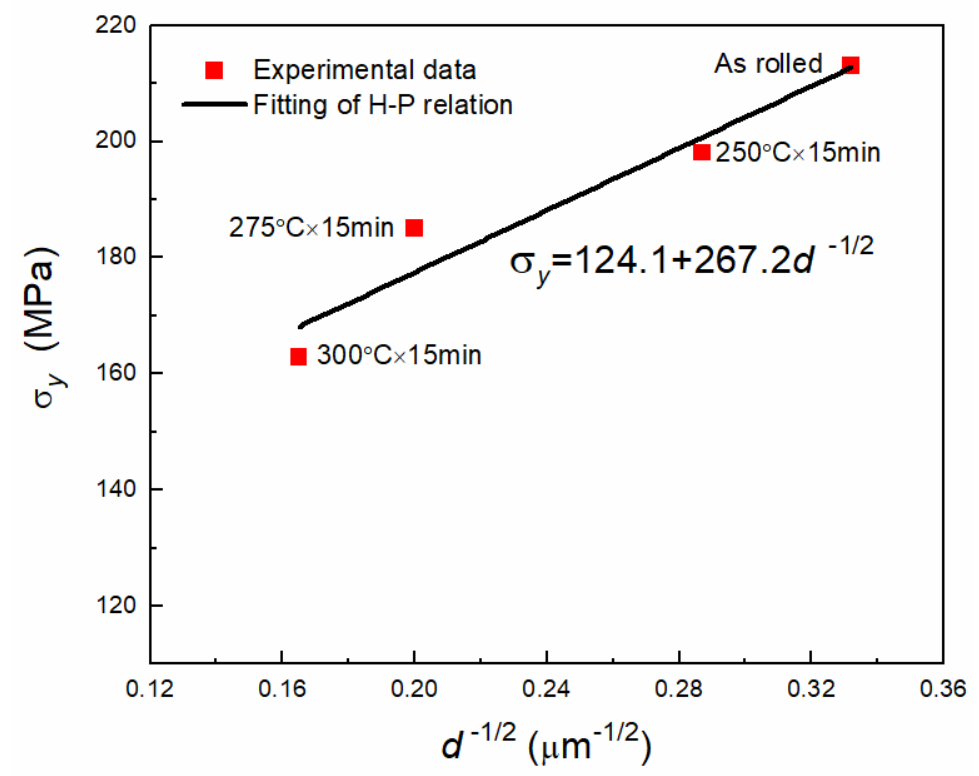

Figure 9. Hall-Petch relationship for the $\mathrm{Mg}-6 \mathrm{Al}$ plates in as-rolled and post-heat-treated conditions.

The effect of texture on YS and $\sigma_{y}$ can also be explained by a variation of the Schmid Factor (SF) of the basal slip system, given by the following equation [46]:

$$
\tau_{C R S S}=m \times \sigma_{y}
$$

where $\tau_{C R S S}$ is the critical resolved shear stress (CRSS), $\sigma_{y}$ is the stress applied on the material, and $m$ is the Schmid Factor, which can be expressed as $m=\cos \alpha \times \cos \beta$, where $\alpha$ is the angle between the slip direction and the axis of the external force and $\beta$ is the angle between the slip plane and the axis of the external force. It is known that for the tensile specimens, the value of $m$ was in the range of $0 \sim 0.5$. The basal slip system (0001) $\{11 \overline{2} 0\}$ would be easily activated under a situation where $m$ has a higher value, which induces a lower YS and higher elongation [47]. The Schmid Factor values of the basal slip system in three directions for the as-rolled and annealed plates were calculated and are shown in Figure 10. It can be seen that there was not much difference in the $m$ values between the as-rolled and annealed plates at $250{ }^{\circ} \mathrm{C}$, while the $m$ values for the plates annealed at 275 and $300{ }^{\circ} \mathrm{C}$ evidently increased. However, the grain sizes of the plate annealed at $300{ }^{\circ} \mathrm{C}(36.6 \mu \mathrm{m})$ were much larger than those annealed at $275^{\circ} \mathrm{C}(24.8 \mu \mathrm{m})$. Therefore, combining all factors, the plate annealed at $275^{\circ} \mathrm{C}$ achieved the best overall mechanical properties.

Figure 11 shows optical micrographs of the microstructures near the fracture surface of the post-tensile tested specimens (tensioned along RD) from the as-rolled and annealed plates. The fracture surfaces were first partially polished to reveal in better detail the morphology of the grain interiors. A high density of twins can be observed in all specimens (as indicated by red arrows). Note the many micro-cracks in the specimen from the plate annealed at $300{ }^{\circ} \mathrm{C}$. In addition, in Figure 4 , no coarse second phase particles $(>1 \mu \mathrm{m})$ were observed in the as-rolled and annealed plates, so no crack initiation could have occurred near second phase precipitates in the tested specimens. Therefore, the fracture mechanism of the plates is anticipated to be more closely related to the material's twinning behavior during the tension process. 


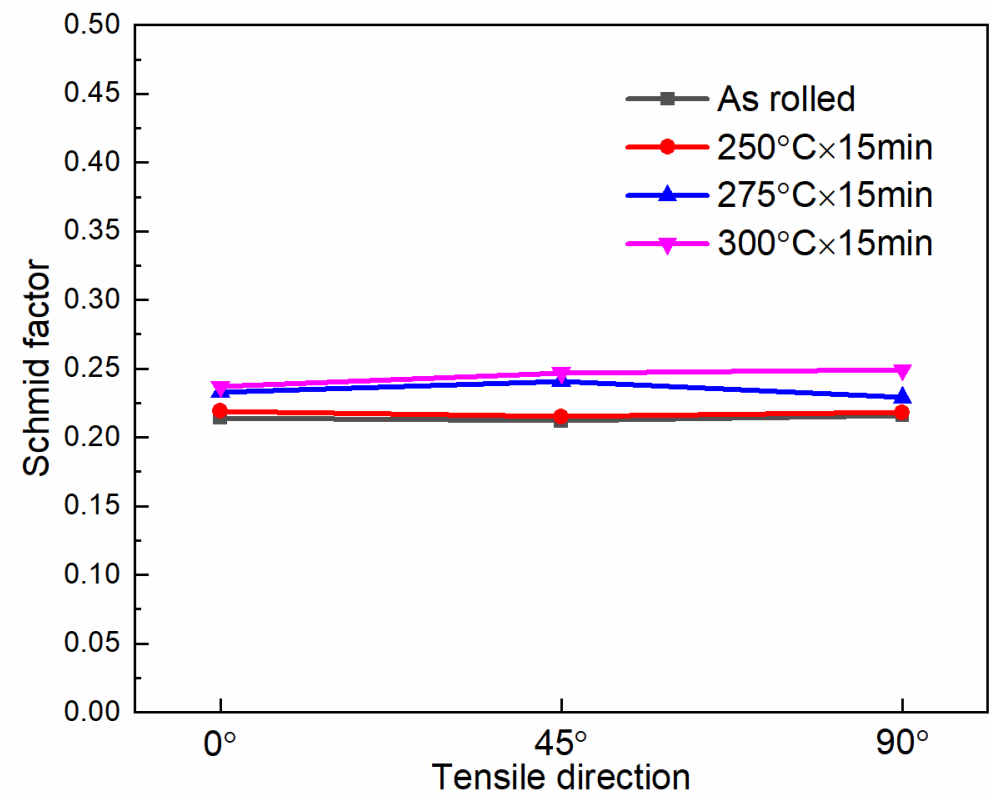

Figure 10. The Schmid Factor value of the as-rolled and annealed plates along the three tensile directions.
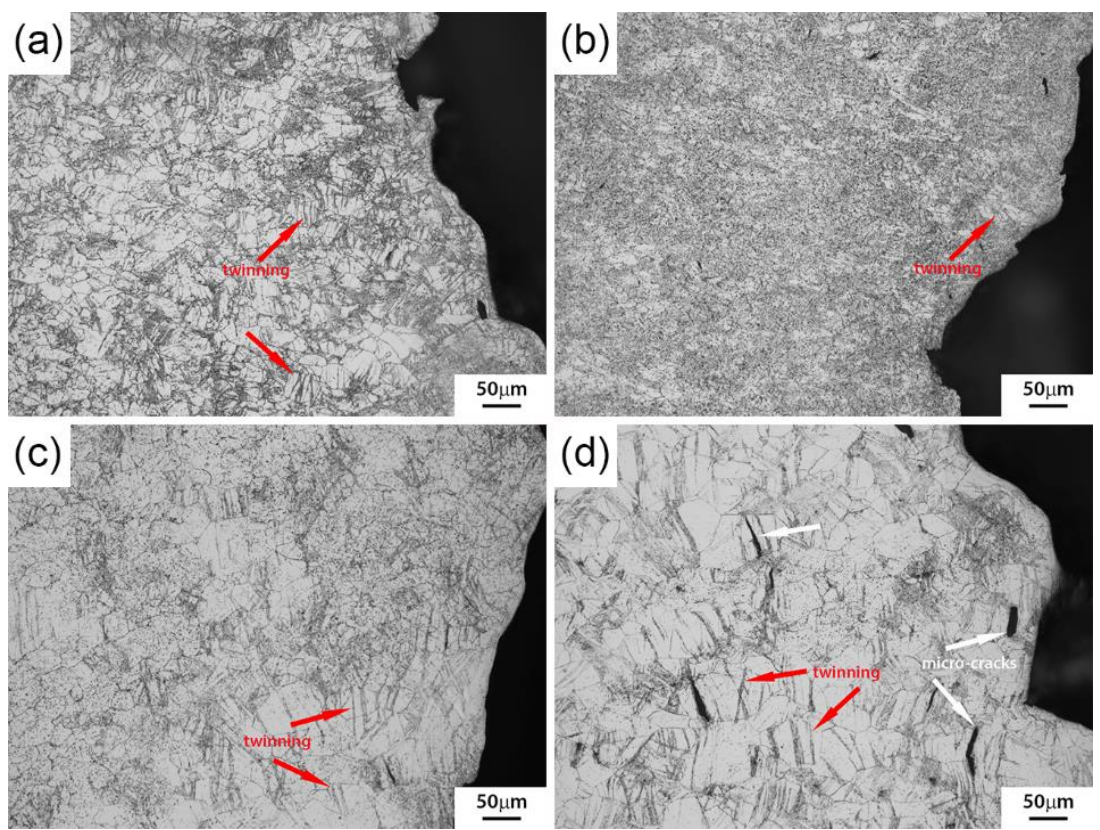

Figure 11. Fracture surfaces of the plates: (a) as-rolled, annealed at (b) $250{ }^{\circ} \mathrm{C}$, (c) $275^{\circ} \mathrm{C}$, and (d) $300^{\circ} \mathrm{C}$ for a fixed time of $15 \mathrm{~min}$. The red arrows indicate twinned grains. The white arrows indicate the micro-cracks along the twin boundaries.

As such, in order to determine the type of twins present, the subsurface morphology of the grains near necking area of a specimen (tensioned along RD) from the plate annealed at $300{ }^{\circ} \mathrm{C}$ was further analyzed by EBSD, as shown in Figure 12a. The misorientation angle distribution shows three different peaks (as indicated by the black arrows in Figure 12b). To further reveal the twin types, the grain boundaries are marked by different colors (Figure 12c). According to the misorientation relationships between the twins and the matrix [48], the twin types can be effectively identified. Specifically, the misorientation angles of $38^{\circ}, 56^{\circ}$, and $86^{\circ}$ represent $\{10 \overline{1} 1\}-\{10 \overline{1} 2\}$ double twinning, $\{10 \overline{1} 1\}$ compression twinning, and $\{10 \overline{1} 2\}$ tension twining, respectively. In this case, all three different kinds of twins were observed (see Figure 12c). In rolled and annealed plates with typically strong basal textures, the $\{10 \overline{1} 1\}$ compression and the $\{10 \overline{1} 1\}-\{10 \overline{1} 2\}$ double twins can easily form because the c-axes 
of most grains are all perpendicular to the axis of the tensile stress $[49,50]$. (Note that the tensile specimens were all in the plane of the DSR plates.) As expected, the stress-strain profiles of the samples lack the characteristic sigmoidal shape associated with deformation twinning and, instead, are indicative of a slip-based deformation behavior. Therefore, coupled with an exhausted work-hardening capacity, the occurrence and formation of these twins must occur at the late stages of the deformation process. In turn, this leads to the onset of shear failure due to the combined effects of strain softening and localized twin-sized void formation. Since the CRSS for twinning decreases with increasing grain size [51], twinning becomes easier in the coarser grained materials. Indeed, the samples annealed at higher temperatures (larger grain sizes) had higher numbers of twins. Due to the incompatibilities between the deformation of the twinned interface and the matrix, the continued increase in local stresses is prone to induce micro-cracks. It was thus expected that a larger number of micro-cracks would be observed in the plate annealed at $300^{\circ} \mathrm{C}$, wherein there was correspondingly less fracture elongation.

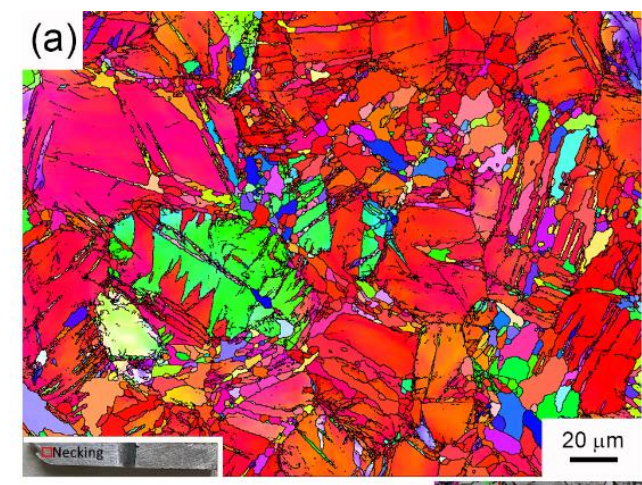

(b)
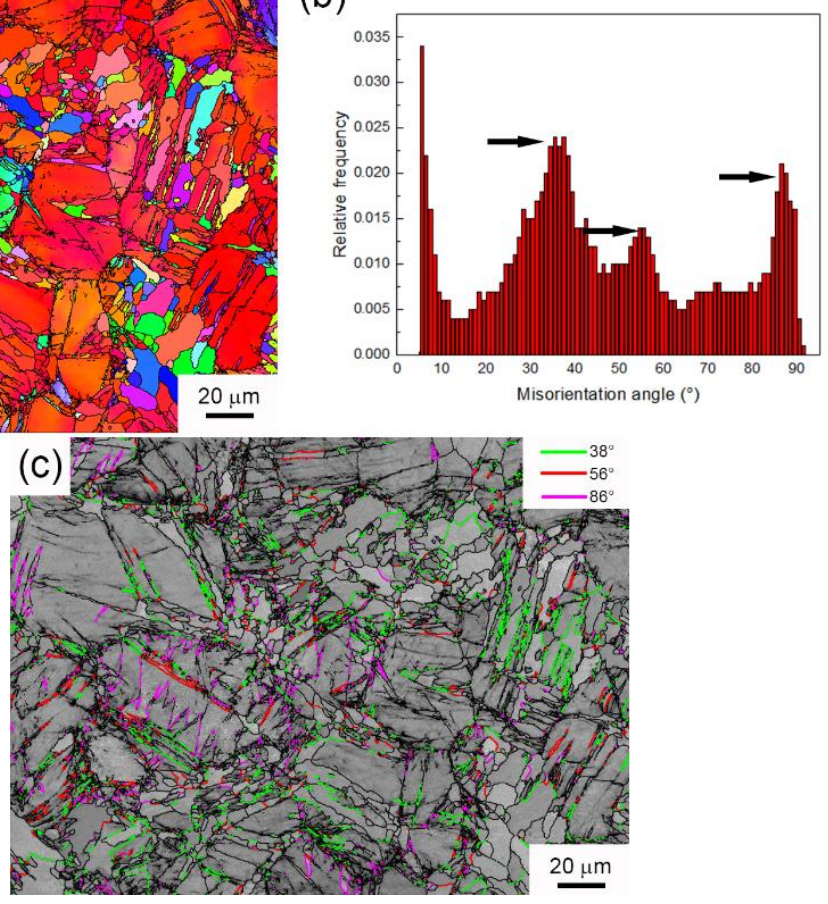

Figure 12. EBSD analysis of the area near the fracture surface of the tensile specimen from a plate annealed at $300{ }^{\circ} \mathrm{C}$ : IPF map in (a), misorientation angle distribution in (b), and grain boundary and twin type analysis in (c).

The combination of DSR and annealing produced Mg-6 Al alloys with a strong basal texture and isotropic in-plane mechanical properties and with relatively high strength and enhanced ductility. It appears that late-stage twinning deformation (mostly extension and double twinning) induces failure that is more prominent at larger grain sizes. While the onset of twinning in the DSR Mg-6 Al samples needs closer examination, the information gained in this study is nevertheless highly useful for developing better design strategies for optimizing the properties of future Mg alloys.

\section{Conclusions}

$\mathrm{Mg}-6 \mathrm{Al}$ alloy plates were preheated at $315^{\circ} \mathrm{C}$ and subsequently rolled at $265^{\circ} \mathrm{C}$ with a speed ratio of 2 via DSR with a total thickness reduction of $50 \%$. The as-rolled plates were subjected to annealing at temperatures of 250,275 , and $300^{\circ} \mathrm{C}$ (holding time $15 \mathrm{~min}$ ). The 
microstructure, texture, and mechanical properties of those plates were investigated. The main conclusions are summarized as follows:

(1) During DSR processing, DRX occurred, leading to the refinement of the microstructure. The grain size was greatly reduced to about $9.1 \mu \mathrm{m}$ compared to the very large grain size of the initially homogenized condition. Subsequent annealing caused grain growth, resulting in an increase in grain size to $12.1,24.8$, and $36.6 \mu \mathrm{m}$ for the plates annealed at 250,275 , and $300^{\circ} \mathrm{C}$, respectively.

(2) The $\{0001\}$ basal texture of the as-rolled plate was tilted in the $\mathrm{RD}$ at $\sim 20^{\circ}$ due to the shear strain introduced during the DSR processing. After annealing, grain growth reduced the basal texture inclination, while the pole intensity slightly increased.

(3) For the plates annealed at 250 and $300{ }^{\circ} \mathrm{C}$, there was a decrease in strength but an improvement in elongation compared with the as-rolled plate. Nevertheless, the plate annealed at $275^{\circ} \mathrm{C}$ demonstrated the best combination of mechanical properties, where the ultimate tensile strength, yield strength, and elongation to failure were observed to be 292.1 $\mathrm{MPa}$, 185.0 MPa, and $24.9 \%$, respectively.

Supplementary Materials: The following are available online at https:/ /www.mdpi.com/article/10 $.3390 /$ met11060926/s1. Figure S1. A schematic showing the 5 different positions for EBSD analysis. Figure S2. Inverse pole figure maps on the $\mathrm{RD}$ plane of the as-rolled plate at different positions across the thickness: (a) upper, (b) upper quarter, (c) center, (d) lower quarter, and (e) lower position; and (f) shows the average grain size at these positions. Figure $\mathrm{S} 3$. Inverse pole figure maps on the RD plane of the annealed plate $\left(250^{\circ} \mathrm{C}\right)$ at different positions across the thickness: (a) upper, (b) upper quarter, (c) center, (d) lower quarter, and (e) lower position; and (f) shows the average grain size at these positions. Figure S4. Inverse pole figure maps on the RD plane of the annealed plate $\left(275^{\circ} \mathrm{C}\right)$ at different positions across the thickness: (a) upper, (b) upper quarter, (c) center, (d) lower quarter, and (e) lower position; and (f) shows the average grain size at these positions. Figure S5. Inverse pole figure maps on the $\mathrm{RD}$ plane of the annealed plate $\left(300{ }^{\circ} \mathrm{C}\right)$ at different positions across the thickness: (a) upper, (b) upper quarter, (c) center, (d) lower quarter, and (e) lower position; and (f) shows the average grain size at these positions. Figure S6. \{0001\} pole figures of the as-rolled plate at different positions across the thickness: (a) upper, (b) upper quarter, (c) center, (d) lower quarter, and (e) lower position; and (f) shows the maximum pole intensities at these positions. Figure S7. \{0001\} pole figures of the annealed plate $\left(250^{\circ} \mathrm{C}\right)$ at different positions across the thickness: (a) upper, (b) upper quarter, (c) center, (d) lower quarter, and (e) lower position; and (f) shows the maximum pole intensities at these positions. Figure S8. 0001$\}$ pole figures of the annealed plate $\left(275^{\circ} \mathrm{C}\right)$ at different positions across the thickness: (a) upper, (b) upper quarter, (c) center, (d) lower quarter, and (e) lower position; and (f) shows the maximum pole intensities at these positions. Figure S9. \{0001\} pole figures of the annealed plate $\left(300^{\circ} \mathrm{C}\right)$ at different positions across the thickness: (a) upper, (b) upper quarter, (c) center, (d) lower quarter, and (e) lower position; and (f) shows the maximum pole intensities at these positions.

Author Contributions: Experiments, H.Z.; data analysis, H.Z. and S.Y.; writing—original draft, H.Z.; writing-review and editing, Z.X. and L.J.K.; supervision, J.S. All authors have read and agreed to the published version of the manuscript.

Funding: The research was funded by The Materials in Extreme Dynamic Environments (MEDE) cooperative agreement (W911NF-12-2-0022). The NCA\&T project number is 290959.

Institutional Review Board Statement: Not applicable.

Informed Consent Statement: Not applicable.

Data Availability Statement: Not applicable.

Acknowledgments: This work was supported by the "Tailoring Mg-alloy Systems through Composition, Microstructure, Severe Plastic Deformation for Army Extreme Dynamic Environment Applications" project.

Conflicts of Interest: The authors declare no conflict of interest. 


\section{References}

1. Li, N.; Zheng, Y. Novel magnesium alloys developed for biomedical application: A review. J. Mater. Sci. Technol. 2013, 29, 489-502. [CrossRef]

2. Ren, L.; Fan, L.; Zhou, M.; Guo, Y.; Zhang, Y.; Boehlert, C.J.; Quan, G. Magnesium application in railway rolling stocks: A new challenge and opportunity for lightweighting. Int. J. LTWT. Mater. Manuf. 2018, 1, 81-88. [CrossRef]

3. Homma, T.; Kunito, N.; Kamado, S. Fabrication of Extraordinary High-Strength Magnesium Alloy by Hot Extrusion. Scr. Mater. 2009, 61, 644-647. [CrossRef]

4. Muralidhar, A.; Narendranath, S.; Nayaka, H.S. Effect of Equal Channel Angular Pressing on AZ31 Wrought Magnesium Alloys. J. Magnes. Alloy 2013, 1, 336-340. [CrossRef]

5. Lee, J.; Konno, T.; Jeong, H. Grain Refinement and Texture Evolution in AZ31 Mg Alloys Sheet Processed by Differential Speed Rolling. Mater. Sci. Eng. B 2009, 161, 166-169. [CrossRef]

6. Kim, W.; Hwang, B.; Lee, M.; Park, Y. Effect of Speed-Ratio on Microstructure, and Mechanical Properties of Mg-3Al-1Zn Alloy, in Differential Speed Rolling. J. Alloy Compd. 2011, 509, 8510-8517. [CrossRef]

7. Kwak, T.; Lim, H.; Han, S.; Kim, W. Refinement of the Icosahedral Quasicrystalline Phase and the Grain Size of Mg-9.25Zn-1.66Y Alloy by High-Ratio Differential Speed Rolling. Scr. Mater. 2015, 103, 49-52. [CrossRef]

8. Park, J.-J. Finite-Element Analysis of Severe Plastic Deformation in Differential-Speed Rolling. Comput. Mater. Sci. 2015, 100, 61-66. [CrossRef]

9. Huang, X.; Suzuki, K.; Watazu, A.; Shigematsu, I.; Saito, N. Improvement of Formability of Mg-Al-Zn Alloy Sheet at Low Tem-Peratures Using Differential Speed Rolling. J. Alloy Compd. 2009, 470, 263-268. [CrossRef]

10. Kim, W.Y.; Kim, W.J. Fabrication of Ultrafine-Grained Mg-3Al-1Zn Magnesium Alloy Sheets Using a Continuous High-Ratio Differ-Ential Speed Rolling Technique. Mater. Sci. Eng. A 2014, 594, 189-192. [CrossRef]

11. Huang, X.; Suzuki, K.; Watazu, A.; Shigematsu, I.; Saito, N. Effects of thickness reduction per pass on microstructure and texture of Mg-3Al-1Zn alloy sheet processed by differential speed rolling. Scr. Mater. 2009, 60, 964-967. [CrossRef]

12. Kim, W.; Lee, K.; Choi, S.-H. Mechanical Properties and Microstructure of Ultra Fine-Grained Copper Prepared by a High-SpeedRatio Differential Speed Rolling. Mater. Sci. Eng. A 2009, 506, 71-79. [CrossRef]

13. Gong, X.; Kang, S.B.; Li, S.; Cho, J.H. Enhanced Plasticity of Twin-Roll Cast ZK60 Magnesium Alloy through Differential Speed Rolling. Mater. Des. 2009, 30, 3345-3350. [CrossRef]

14. Huang, X.; Suzuki, K.; Saito, N. Microstructure and Mechanical Properties of AZ80 Magnesium Alloy Sheet Processed by Differential Speed Rolling. Mater. Sci. Eng. A 2009, 508, 226-233. [CrossRef]

15. Liu, H.; Tang, D.; Cai, Q.; Li, Z. Texture of AZ31B Magnesium Alloy Sheets Produced by Differential Speed Rolling Technologies. Rare Met. 2012, 31, 415-419. [CrossRef]

16. Cho, J.-H.; Jeong, S.S.; Kim, H.-W.; Kang, S.-B. Texture and Microstructure Evolution during the Symmetric and Asymmetric Rolling of AZ31B Magnesium Alloys. Mater. Sci. Eng. A 2013, 566, 40-46. [CrossRef]

17. Huang, X.; Suzuki, K.; Watazu, A.; Shigematsu, I.; Saito, N. Microstructure and Texture of Mg-Al-Zn Alloy Processed by Dif-Ferential Speed Rolling. J. Alloy Compd. 2008, 457, 408-412. [CrossRef]

18. Zheng, L.; Nie, H.; Liang, W.; Wang, H.; Wang, Y. Effect of pre-homogenizing treatment on microstructure and mechanical properties of hot-rolled AZ91 magnesium alloys. J. Magnes. Alloy 2016, 4, 115-122. [CrossRef]

19. Chang, L.; Cho, J.; Kang, S. Microstructure and Mechanical Properties of AM31 Magnesium Alloys Processed by Differential Speed Rolling. J. Mater. Process. Technol. 2011, 211, 1527-1533. [CrossRef]

20. Chang, L.; Cho, J.; Kang, S. Microstructure and Mechanical Properties of Twin Roll Cast AM31 Magnesium Alloy Sheet Processed by Differential Speed Rolling. Mater. Des. 2012, 34, 746-752. [CrossRef]

21. Wang, X.; Chen, W.-Z.; Hu, L.-X.; Wang, G.-J.; Wang, E.-D. Microstructure Refining and Property Improvement of ZK60 Magne-Sium Alloy by Hot Rolling. Trans. Nonferrous Metals Soc. China 2011, 21, S242-S246. [CrossRef]

22. Chen, H.; Yu, H.; Kang, S.B.; Cho, J.H.; Min, G. Optimization of Annealing Treatment Parameters in a Twin Roll Cast and Warm Rolled ZK60 Alloy Sheet. Mater. Sci. Eng. A 2010, 527, 1236-1242. [CrossRef]

23. Kim, W.; Kim, M.; Wang, J. Superplastic Behavior of a Fine-Grained ZK60 Magnesium Alloy Processed by High-Ratio Differential Speed Rolling. Mater. Sci. Eng. A 2009, 527, 322-327. [CrossRef]

24. Watanabe, H.; Mukai, T.; Ishikawa, K. Differential speed rolling of an AZ31 magnesium alloy and the resulting mechanical properties. J. Mater. Sci. 2004, 39, 1477-1480. [CrossRef]

25. Miao, Q.; Hu, L.; Wang, G.; Wang, E. Fabrication of Excellent Mechanical Properties AZ31 Magnesium Alloy Sheets by Conventional Rolling and Subsequent Annealing. Mater. Sci. Eng. A 2011, 528, 6694-6701. [CrossRef]

26. Kim, W.; Lee, J.; Jeong, H. Microstructure and Mechanical Properties of Mg-Al-Zn Alloy Sheets Severely Deformed by Asymmetrical Rolling. Scr. Mater. 2007, 56, 309-312. [CrossRef]

27. Yang, P.; Guo, X.-F.; Yang, K.-J. Effect of Heat Treatment on Microstructure and Microhardness of Rapidly Solidified ZK60 Mag-Nesium Ribbons. Trans. Mater. Heat Treat. 2010, 31, 1-5.

28. Chen, X.; Pan, F.; Mao, J.; Wang, J.; Zhang, D.; Tang, A.; Peng, J. Effect of Heat Treatment on Strain Hardening of ZK60 Mg Alloy. Mater. Des. 2011, 32, 1526-1530. [CrossRef]

29. Yoshihara, S.; Yamamoto, H.; Manabe, K.; Nishimura, H. Formability Enhancement in Magnesium Alloy Deep Drawing by Local Heating and Cooling Technique. J. Mater. Process. Technol. 2003, 143-144, 612-615. [CrossRef] 
30. Wang, J.; Jang, Y.; Wan, G.; Giridharan, V.; Song, G.-L.; Xu, Z.; Koo, Y.; Qi, P.; Sankar, J.; Huang, N.; et al. Flow-Induced Corrosion of Absorbable Magnesium Alloy: In-Situ and Real-Time Electrochemical Study. Corros. Sci. 2016, 104, 277-289. [CrossRef]

31. Ko, Y.G.; Hamad, K. Structural Features and Mechanical Properties of AZ31 Mg Alloy Warm-Deformed by Differential Speed Rolling. J. Alloy Compd. 2018, 744, 96-103. [CrossRef]

32. Kleiner, S.; Beffort, O.; Uggowitzer, P. Microstructure Evolution during Reheating of an Extruded Mg-Al-Zn Alloy into the Semisolid State. Scr. Mater. 2004, 51, 405-410. [CrossRef]

33. Pardo, A.; Merino, M.; Coy, A.; Viejo, F.; Arrabal, R.; Feliú, S., Jr. Influence of microstructure and composition on the corrosion behaviour of $\mathrm{Mg}$ / Al alloys in chloride media. Electrochim. Acta 2008, 53, 7890-7902. [CrossRef]

34. Beer, A.; Barnett, M. Microstructural Development during Hot Working of Mg-3Al-1Zn. Met. Mater. Trans. A 2007, 38, 1856-1867. [CrossRef]

35. Al-Samman, T.; Gottstein, G. Dynamic Recrystallization during High Temperature Deformation of Magnesium. Mater. Sci. Eng. A 2008, 490, 411-420. [CrossRef]

36. Yi, S.; Schestakow, I.; Zaefferer, S. Twinning-Related Microstructural Evolution during Hot Rolling and Subsequent Annealing of Pure Magnesium. Mater. Sci. Eng. A 2009, 516, 58-64. [CrossRef]

37. Huang, X.; Suzuki, K.; Chino, Y. Different Annealing Behaviours of Warm Rolled Mg-3Al-1Zn Alloy Sheets With Dynamic Re-Crystallized Microstructure and Deformation Microstructure. Mater. Sci. Eng. A 2013, 560, 232-240. [CrossRef]

38. Wu, W.; Jin, L.; Zhang, Z.; Ding, W.; Dong, J. Grain Growth and Texture Evolution During Annealing in an Indirect-Extruded Mg-1Gd Alloy. J. Alloy Compd. 2014, 585, 111-119. [CrossRef]

39. Yi, S.; Brokmeier, H.-G.; Letzig, D. Microstructural Evolution during the Annealing of an Extruded AZ31 Magnesium Alloy. J. Alloy Compd. 2010, 506, 364-371. [CrossRef]

40. Ion, S.; Humphreys, F.; White, S. Dynamic Recrystallisation and the Development of Microstructure during the High Temperature Deformation of Magnesium. Acta Met. 1982, 30, 1909-1919. [CrossRef]

41. Gong, X.; Kang, S.B.; Cho, J.H.; Li, S. Effect of Annealing on Microstructure and Mechanical Properties of ZK60 Magnesium Alloy Sheets Processed by Twin-Roll Cast and Differential Speed Rolling. Mater. Charact. 2014, 97, 183-188. [CrossRef]

42. Huang, X.; Suzuki, K.; Chino, Y. Static Recrystallization and Mechanical Properties of Mg-4Y-3RE Magnesium Alloy Sheet Pro-Cessed by Differential Speed Rolling at 823K. Mater. Sci. Eng. A 2012, 538, 281-287. [CrossRef]

43. Kim, W.; Park, J. Effect of Differential Speed Rolling on Microstructure and Mechanical Properties of an AZ91 Magnesium Alloy. J. Alloy Compd. 2008, 460, 289-293. [CrossRef]

44. Yu, H.; Xin, Y.; Wang, M.; Liu, Q. Hall-Petch relationship in Mg alloys: A review. J. Mater. Sci. Technol. 2018, 34, 248-256. [CrossRef]

45. Sanchez, C.; Nussbaum, G.; Azavant, P.; Octor, H. Elevated Temperature Behaviour of Rapidly Solidified Magnesium Alloys Con-Taining Rare Earths. Mater. Sci. Eng. A 1996, 221, 48-57. [CrossRef]

46. Chai, L.; Xia, J.; Zhi, Y.; Gou, Y.; Chen, L.; Yang, Z.; Guo, N. Deformation Mode-Determined Misorientation and Microstructural Characteristics in Rolled Pure Zr Sheet. Sci. China Ser. E Technol. Sci. 2018, 61, 1346-1352. [CrossRef]

47. Cepeda-Jiménez, C.; Prado-Martínez, C.; Pérez-Prado, M. Understanding the High Temperature Reversed Yield Asymmetry in a Mg-Rare Earth Alloy by Slip Trace Analysis. Acta Mater. 2018, 145, 264-277. [CrossRef]

48. Nave, M.D.; Barnett, M.R. Microstructures and Textures of Pure Magnesium Deformed in Plane-Strain Compression. Scr. Mater. 2004, 51, 881-885. [CrossRef]

49. Stanford, N.; Barnett, M. Effect of Composition on the Texture and Deformation Behaviour of Wrought Mg Alloys. Scr. Mater. 2008, 58, 179-182. [CrossRef]

50. Jiang, M.; Xu, C.; Nakata, T.; Yan, H.; Chen, R.; Kamado, S. High-Speed Extrusion of Dilute Mg-Zn-Ca-Mn Alloys and Its Effect on Microstructure, Texture and Mechanical Properties. Mater. Sci. Eng. A 2016, 678, 329-338. [CrossRef]

51. Jain, A.; Duygulu, O.; Brown, D.; Tomé, C.; Agnew, S. Grain Size Effects on the Tensile Properties and Deformation Mechanisms of a Magnesium Alloy, AZ31B, Sheet. Mater. Sci. Eng. A 2008, 486, 545-555. [CrossRef] 